\section{LESSON 54}

Personal letters to friends

Letter 25

PAPER: A5 (148 × $210 \mathrm{~mm})$.

MARGINS: Suitable.

TARGET TIME: 10 minutes.

Turn up 7 single lines before typing the address of the person sending this personal letter.

Remember not to type the sender's name at the foot of personal letters to friends.

Type or write in the instructions and keep this in your folder for future reference. You could type the address of the person sending the letter as in lesson 53.

Letter 26

PAPER: A5 $(148 \times 210 \mathrm{~mm})$.

MARGINS: Suitable.

TARGET TIME: 10 minutes.
When typing a letter to a friend or relative, first type your address at the head of the sheet as in Lesson 53. Once you have typed this, type the date. There is no need to type the name and address of the person you are sending the letter to. Type the Salutation 3 single lines below the date.

At the end of the letter there is no need to type either the complimentary close or the name of the person sending the letter.

\section{Willow Drive, Milford Haven, Pembrokeshire.}

(Turn up 3 single lines)

To-day's date

(Turn up 3 single lines)

Dear Uncle Robert,

(Turn up 2 single lines)

Thank you very much for inviting me to come and stay with you next week-end. Mother says that it is all right for me to come on Friday evening after school and I can stay until tea on Sunday.

I will catch the coach which leaves at 1700 hours and should arrive in Tenby at 1730 hours. Could you please arrange to meet me?

(Turn up 2 single lines)

Best wishes,

From: 62 Chestnut Walk, Sedbergh, Yorkshire. Y04 5cW To-day's date Dear Pat, Just a note to thank you for a super party last night. It was great to see the old gang once more and to be able to catch up on all the news. Eric says he has not enjoyed himself so much for ages. (Paragraph) I hope the enclosed pattern is what you are looking for. Let me know how it works out. I see that suttons have just the right wool in stock at the moment. see you soon.

Type a letter to a friend thanking him or her for an evening spent together. 